\title{
Enhancement of $\mathrm{CeO}_{2}$ Silanization by Spontaneous Breakage of Si-O Bonds through Facet Engineering
}

Hongyang Ma, Hangjuan Ren*, Pramod Koshy, Charles C. Sorrell, and Judy N. Hart*

School of Materials Science and Engineering, UNSW Sydney, NSW 2052, Australia

*Corresponding Authors: hangjuan.ren@unsw.edu.au (H. R), j.hart@unsw.edu.au (J.N. H)

Supporting Information

Table S1. Experimental and calculated lattice parameters and band gaps of $\mathrm{CeO}_{2}$.

\begin{tabular}{ccccc}
\hline \multirow{2}{*}{ Parameters } & \multicolumn{3}{c}{ Lattice parameters / } & \multirow{2}{*}{ Band gap (eV) } \\
\cline { 2 - 4 } & $a$ & $b$ & $c$ & $3.0-3.2$ \\
Experimental $^{1,2}$ & 5.411 & 5.411 & 5.411 & 3.0 \\
Calculated & 5.425 & 5.425 & 5.425 & \\
\hline
\end{tabular}

Table S2. Experimental and calculated structural parameters of the isolated gas-phase TEOS molecule.

\begin{tabular}{ccccccc}
\hline \multirow{2}{*}{ Parameters } & \multicolumn{3}{c}{ Bond lengths / $\AA$} & \multicolumn{3}{c}{ Bond angles } \\
\cline { 2 - 7 } & $\mathrm{Si}-\mathrm{O}$ & $\mathrm{C}-\mathrm{O}$ & $\mathrm{C}-\mathrm{H}$ & $\mathrm{O}-\mathrm{Si}-\mathrm{O}$ & $\mathrm{C}-\mathrm{O}-\mathrm{Si}$ & $\mathrm{C}-\mathrm{C}-\mathrm{O}$ \\
\hline Experimenta $^{3}$ & 1.62 & 1.42 & 1.12 & $115.5^{\circ}$ & $122.3^{\circ}$ & $109.5^{\circ}$ \\
Calculated & 1.67 & 1.42 & 1.10 & $109.0^{\circ}$ & $119.6^{\circ}$ & $109.0^{\circ}$ \\
\hline
\end{tabular}


Table S3. Calculated unrelaxed $\left(E_{\text {unrelaxed }}\right)$ and relaxed $\left(E_{\text {relaxed }}\right)$ surface energies $\left(\mathrm{J} / \mathrm{m}^{2}\right)$ for three low-index surfaces of $\mathrm{CeO}_{2}$.

\begin{tabular}{cccccccc}
\hline \multirow{2}{*}{ Method } & \multicolumn{2}{c}{$\mathrm{CeO}_{2}\{100\}$} & \multicolumn{2}{c}{$\mathrm{CeO}_{2}\{110\}$} & \multicolumn{2}{c}{$\mathrm{CeO}_{2}\{111\}$} & \multirow{2}{*}{ Reference } \\
\cline { 2 - 6 } & $E_{\text {unrelaxed }}$ & $E_{\text {relaxed }}$ & $E_{\text {unrelaxed }}$ & $E_{\text {relaxed }}$ & $E_{\text {unrelaxed }}$ & $E_{\text {relaxed }}$ & \\
\hline DFT & 3.14 & 2.16 & 1.99 & 1.55 & 1.05 & 0.96 & This work \\
LDA & - & - & 1.55 & 1.35 & 1.06 & 1.04 & 4 \\
GGA & 2.05 & 1.41 & 1.26 & 1.01 & 0.69 & 0.68 & 5 \\
PBE0 & - & - & 0.92 & 0.81 & 0.77 & 0.73 & 6 \\
HSE & - & - & - & 0.91 & - & 0.81 & 7 \\
B3LYP & - & 2.11 & - & 1.55 & - & 0.90 & 8 \\
HF & - & - & 2.62 & 2.11 & 1.34 & 1.31 & 9 \\
\hline
\end{tabular}

Table S4. Si-O and $\mathrm{Ce}-\mathrm{O}$ bond lengths in the optimized geometries for SODA-2D on nondefective $\mathrm{CeO}_{2}\{100\}$ facet

\begin{tabular}{|c|c|c|}
\hline Bonds & Length $(\AA)$ & Bond Type \\
\hline \multirow{2}{*}{$\mathrm{Si}$ TEOS $-\mathrm{O}_{\text {surface }}$} & 1.60 & \multirow{6}{*}{$\begin{array}{l}\text { With } \\
\text { residual } \\
\text { TEOS }\end{array}$} \\
\hline & 1.60 & \\
\hline \multirow{2}{*}{$\mathrm{Si}_{\text {TEOS }}-\mathrm{O}_{\text {TEOS }}$} & 1.64 & \\
\hline & 1.73 & \\
\hline \multirow{6}{*}{$\mathrm{Ce}_{\text {surface }}-\mathrm{O}_{\text {TEOS }}$} & 2.62 & \\
\hline & 2.72 & \\
\hline & 2.42 & \multirow{4}{*}{$\begin{array}{c}\text { With } \\
\text { dissociated } \\
\text { fragments }\end{array}$} \\
\hline & 2.44 & \\
\hline & 2.56 & \\
\hline & 2.61 & \\
\hline
\end{tabular}

Table S5. $\mathrm{Si}-\mathrm{O}$ and $\mathrm{Ce}-\mathrm{O}$ bond lengths in the optimized geometries for SODA on defective $\mathrm{CeO}_{2}\{111\}$ facet

\begin{tabular}{|c|c|c|}
\hline Bonds & Length $(\AA)$ & Bond Type \\
\hline $\mathrm{Si}_{\text {TEOS }}-\mathrm{O}_{\text {surface }}$ & 1.60 & \multirow{5}{*}{$\begin{array}{l}\text { With } \\
\text { residual } \\
\text { TEOS }\end{array}$} \\
\hline \multirow{3}{*}{$\mathrm{Si}$ TEOS $-\mathrm{O}_{\mathrm{TEOS}}$} & 1.64 & \\
\hline & 1.66 & \\
\hline & 1.66 & \\
\hline \multirow{4}{*}{$\mathrm{Ce}_{\text {surface }}-\mathrm{O}_{\text {TEOS }}$} & 2.62 & \\
\hline & 2.48 & \multirow{3}{*}{$\begin{array}{c}\text { With } \\
\text { dissociated } \\
\text { fragments }\end{array}$} \\
\hline & 2.55 & \\
\hline & 2.58 & \\
\hline
\end{tabular}



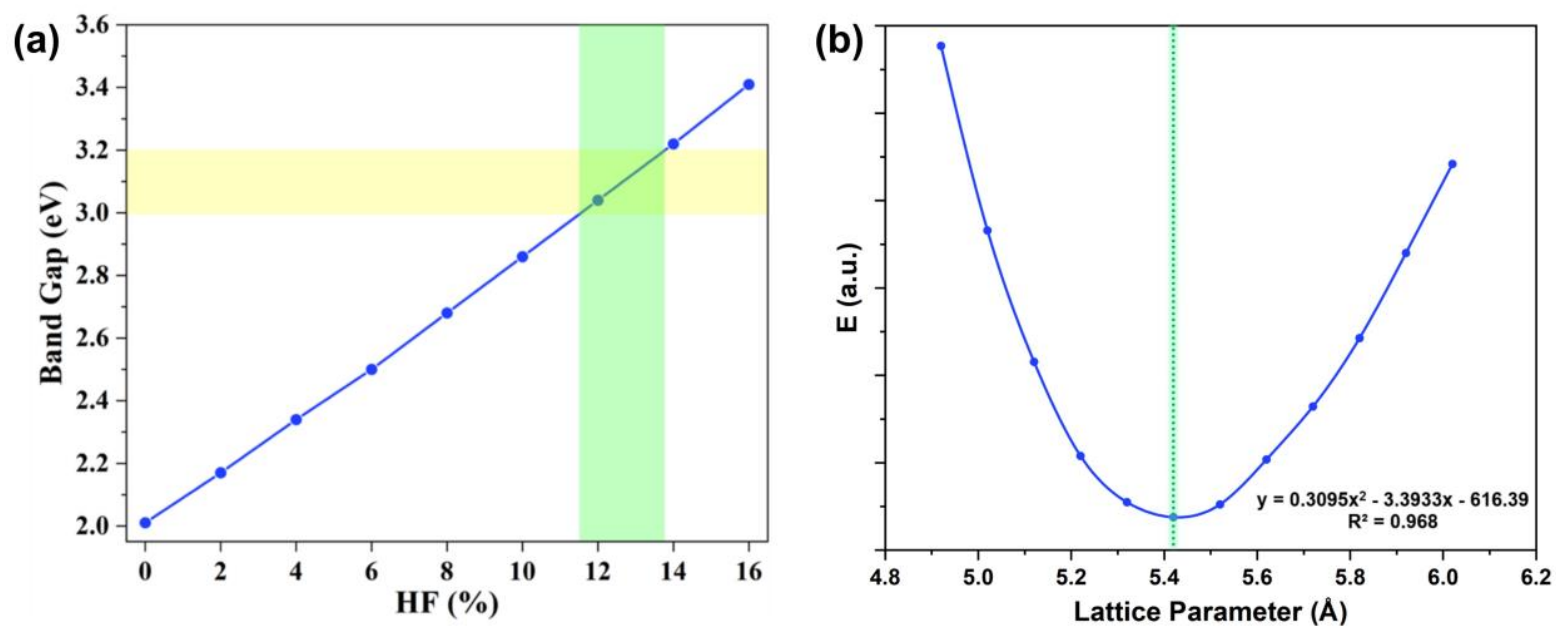

Figure S1. (a) Calculated band gaps as a function of the amount of HF exchange. The highlighted areas represent the optimal range HF to match experimental band gap values ${ }^{1,2}$; (b) total energies as a function of the lattice parameter for bulk $\mathrm{CeO}_{2}$.
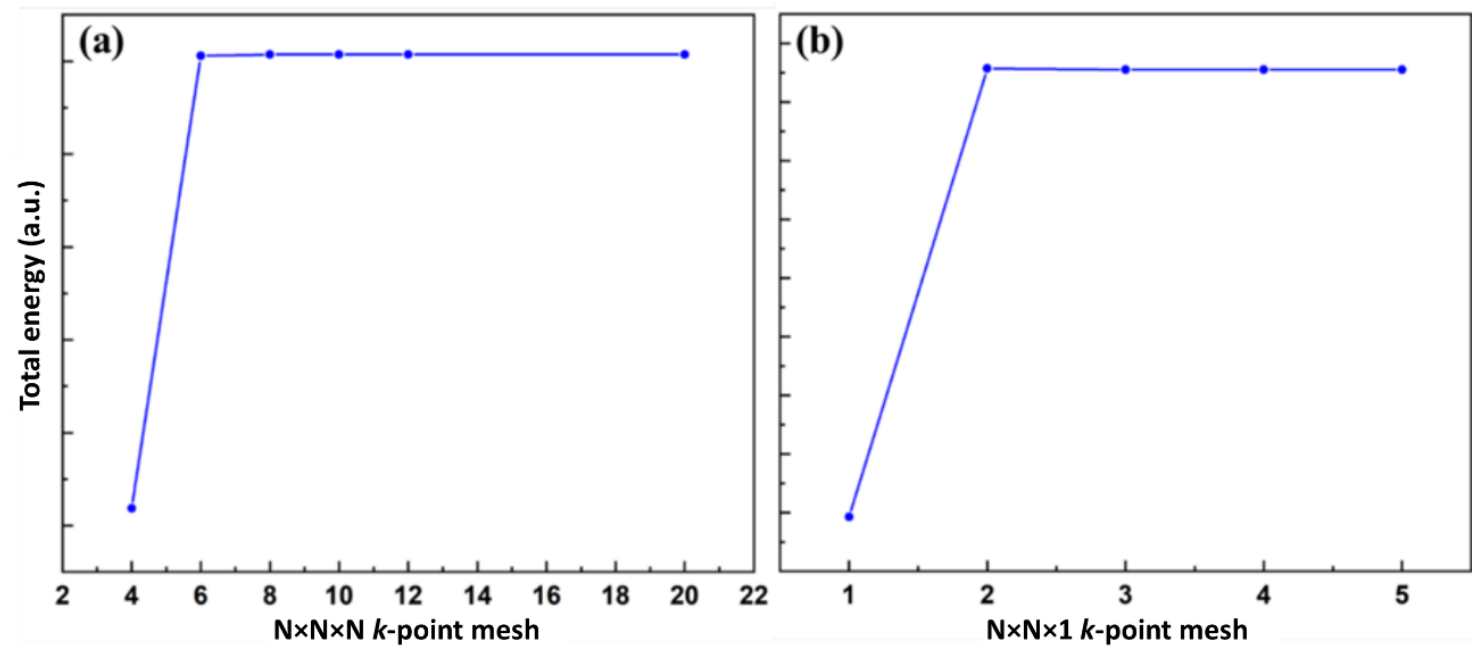

Figure S2. Total energies as a function of the number of k-points: (a) bulk $\mathrm{CeO}_{2}$ and (b) $\mathrm{TEOS} / \mathrm{CeO}_{2}$ system. 


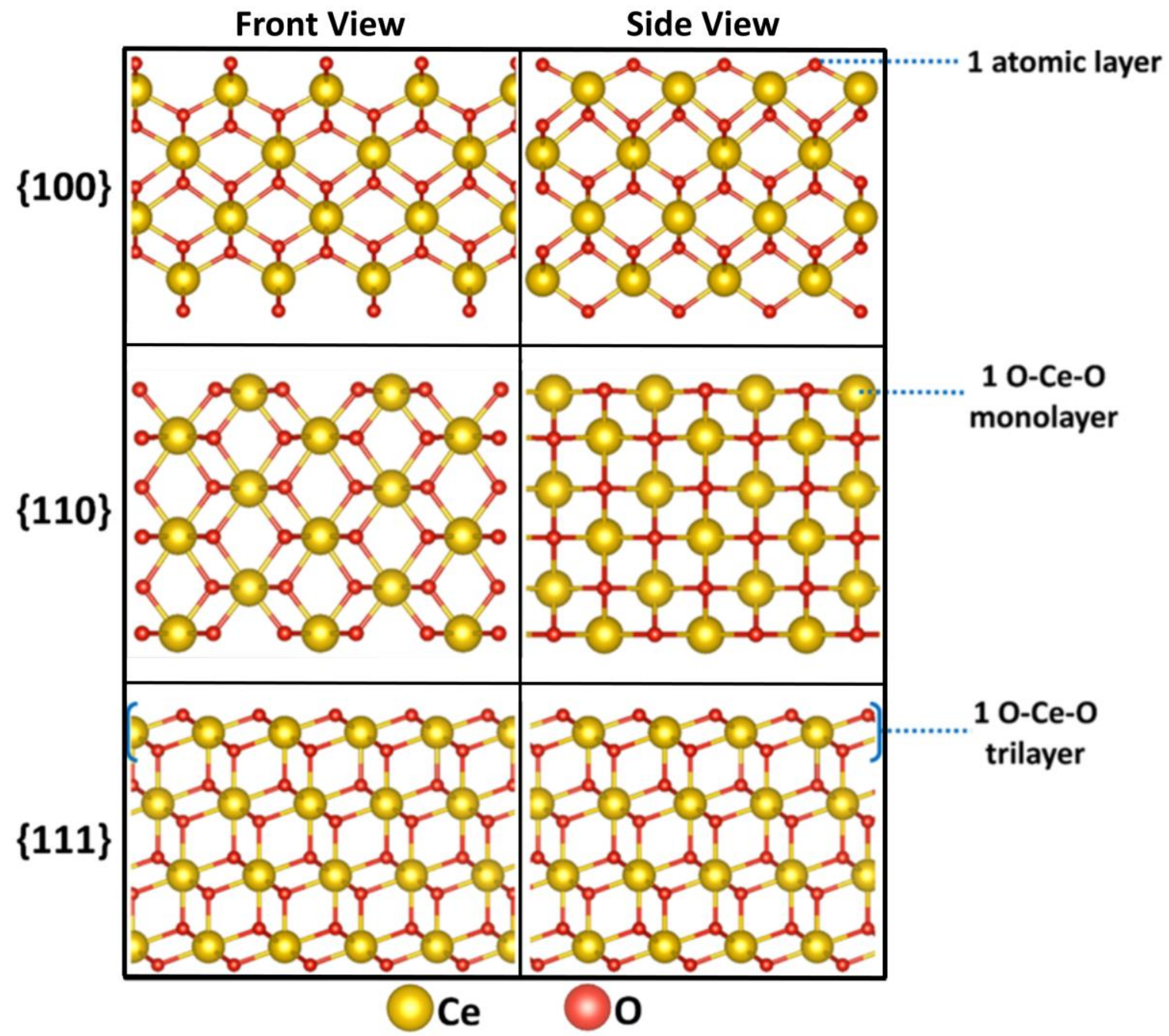

Figure S3. Optimized geometries of the $\mathrm{CeO}_{2}$ slab models, for slabs exposing the $\{100\}$, $\{110\}$, and $\{111\}$ facets. 


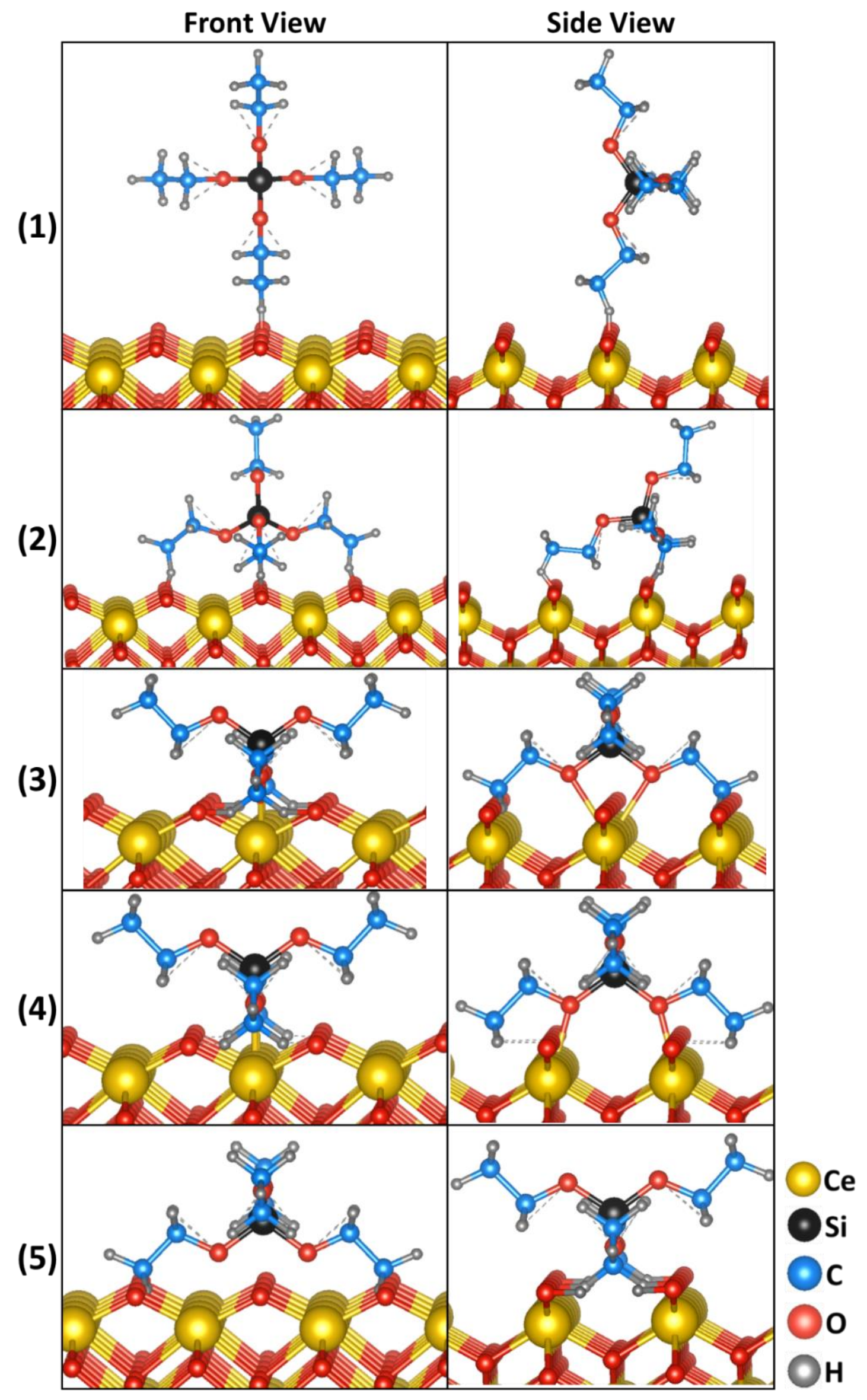




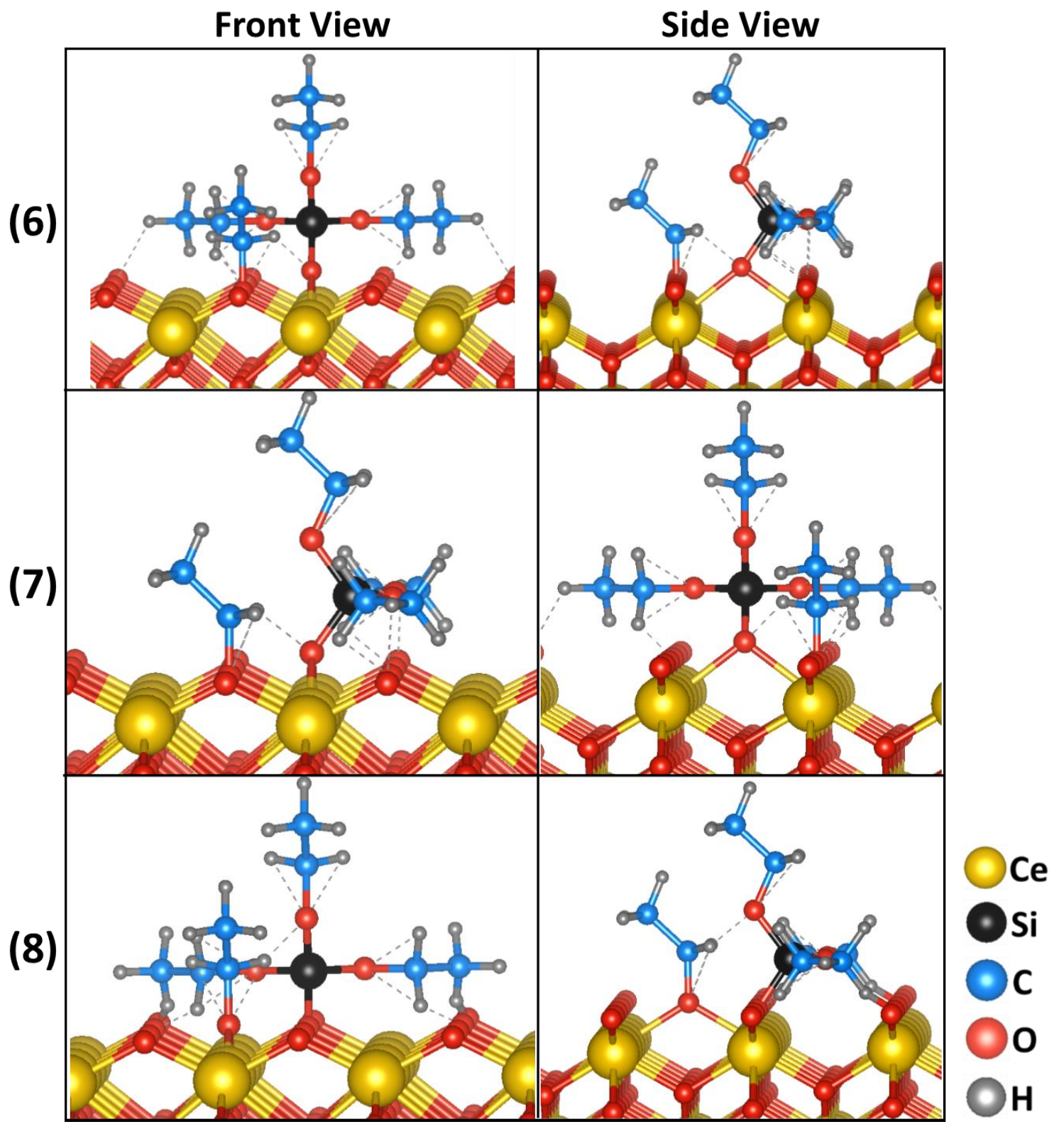

Figure S4. Different input geometries tested for TEOS adsorption on the $\mathrm{CeO}_{2}\{100\}$ facet. 


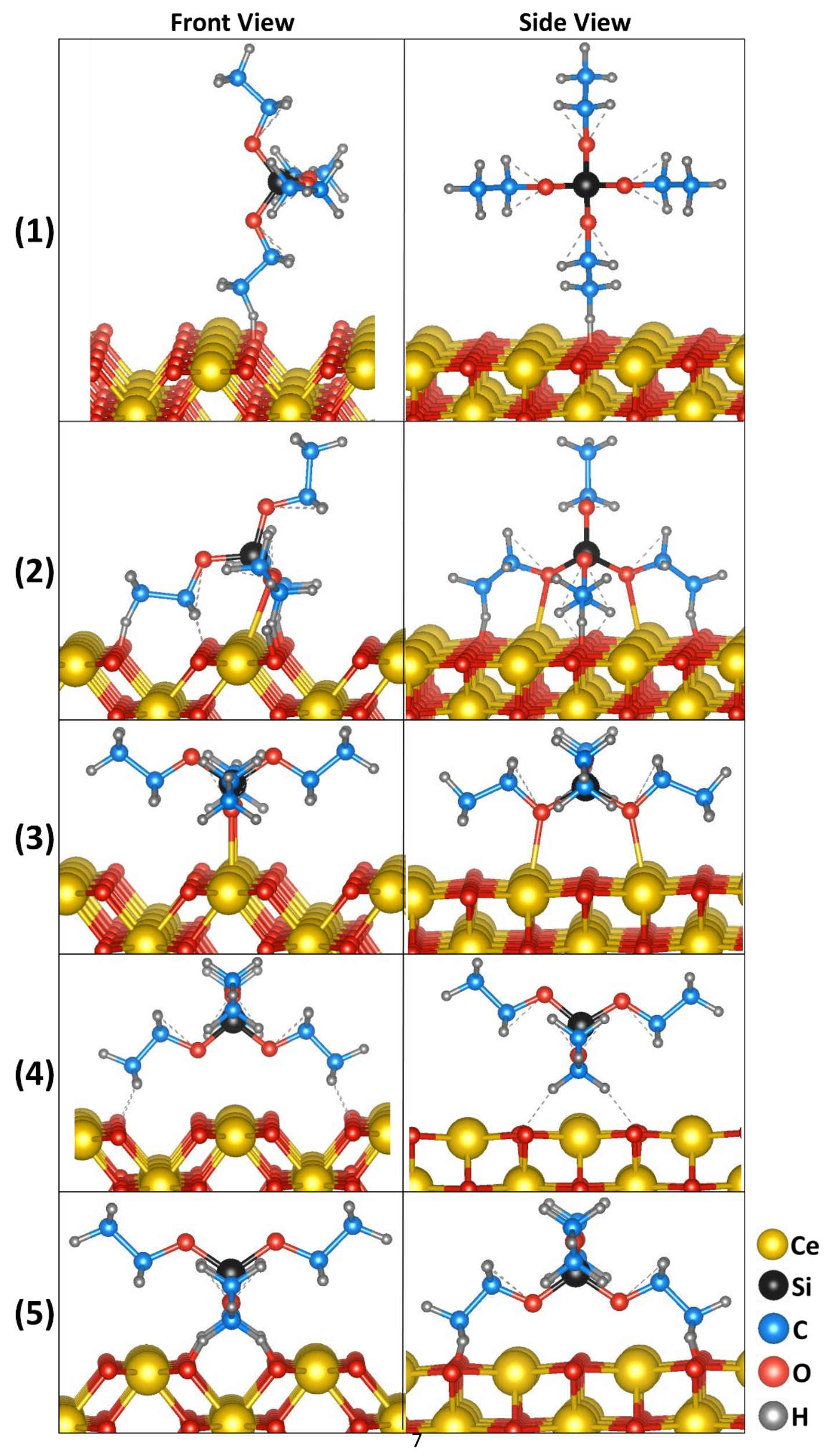




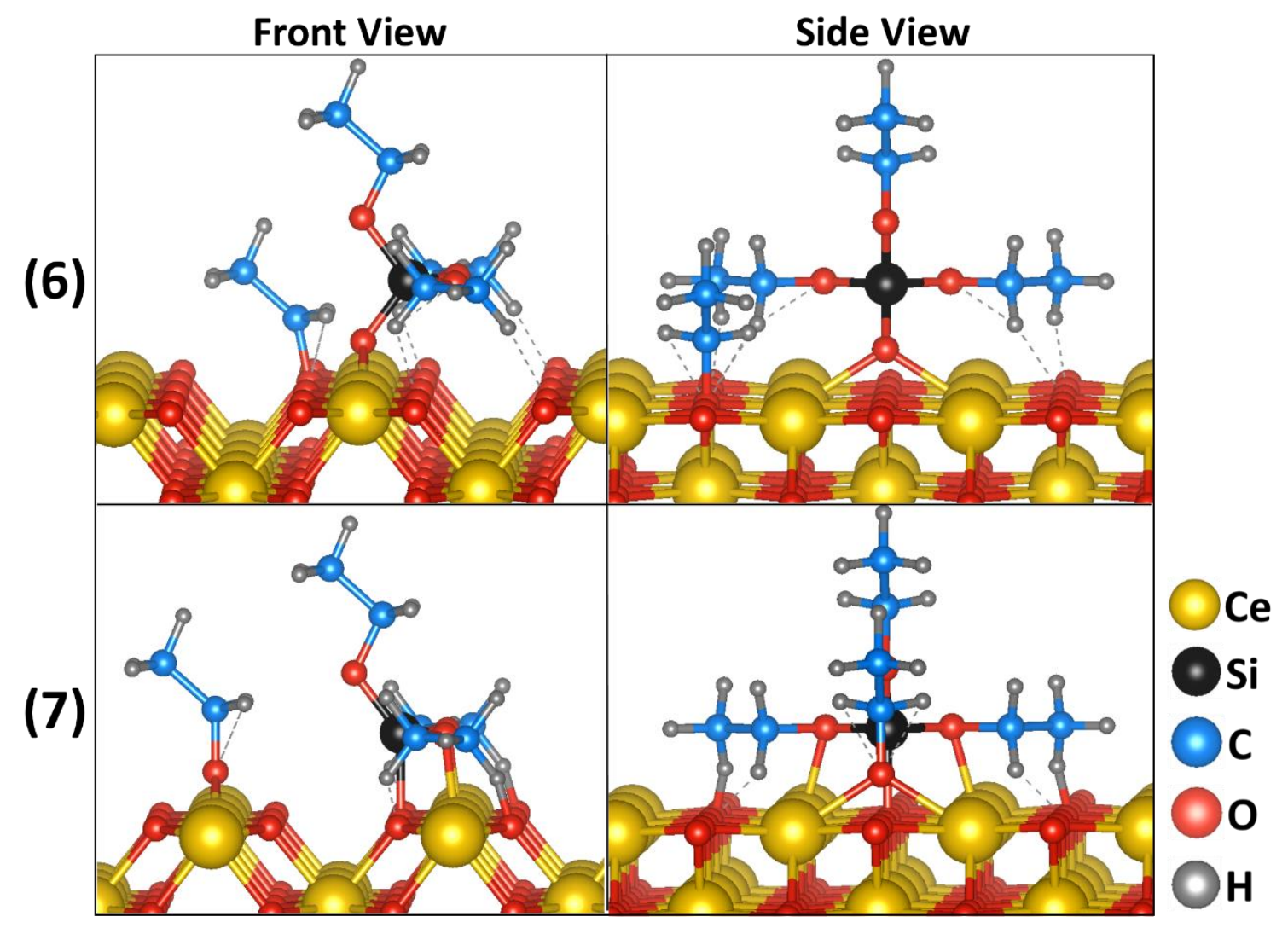

Figure S5. Different input geometries tested for TEOS adsorption on the $\mathrm{CeO}_{2}\{110\}$ facet. 


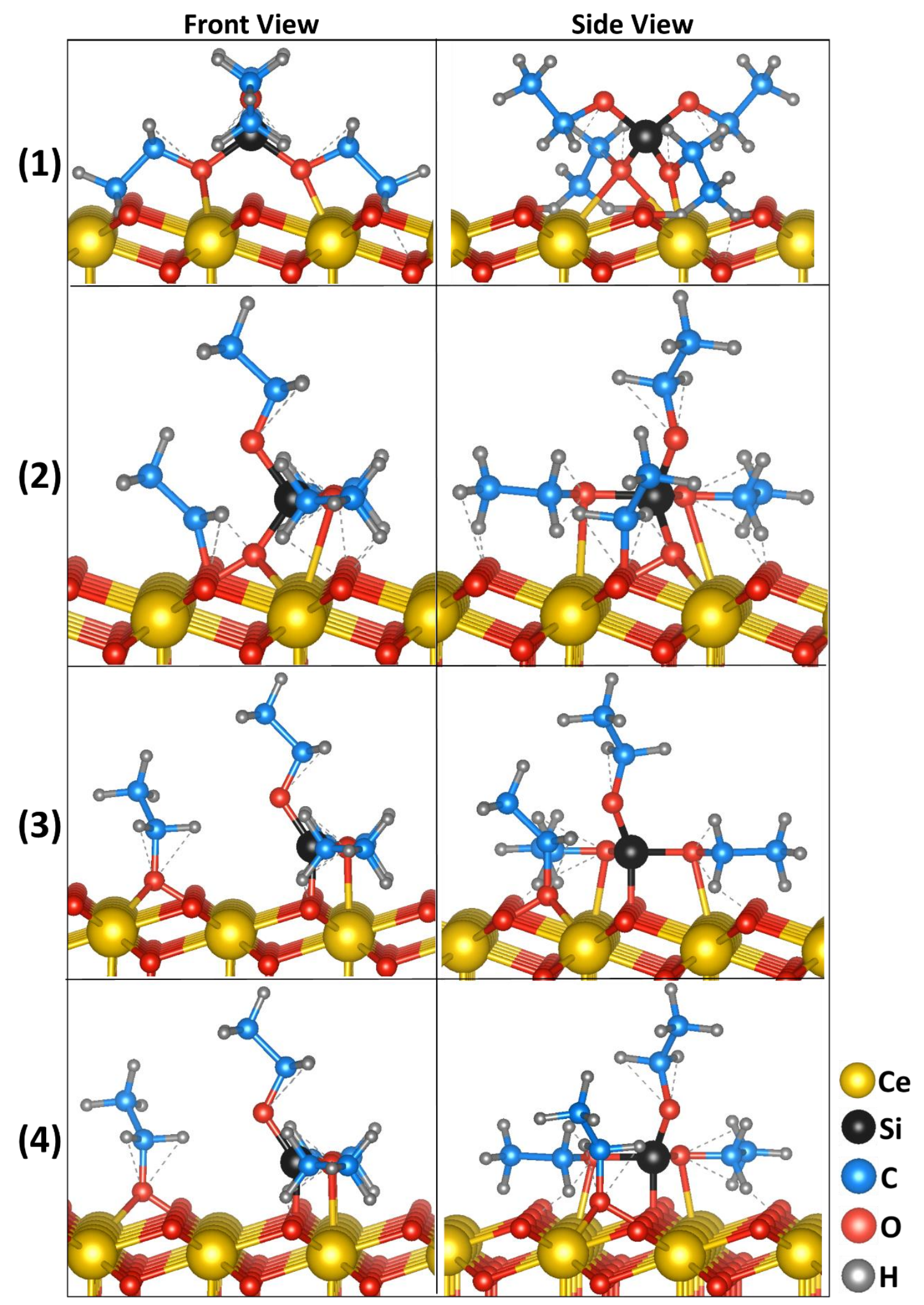

Figure S6. Different input geometries tested for TEOS adsorption on the $\mathrm{CeO}_{2}\{111\}$ facet. 


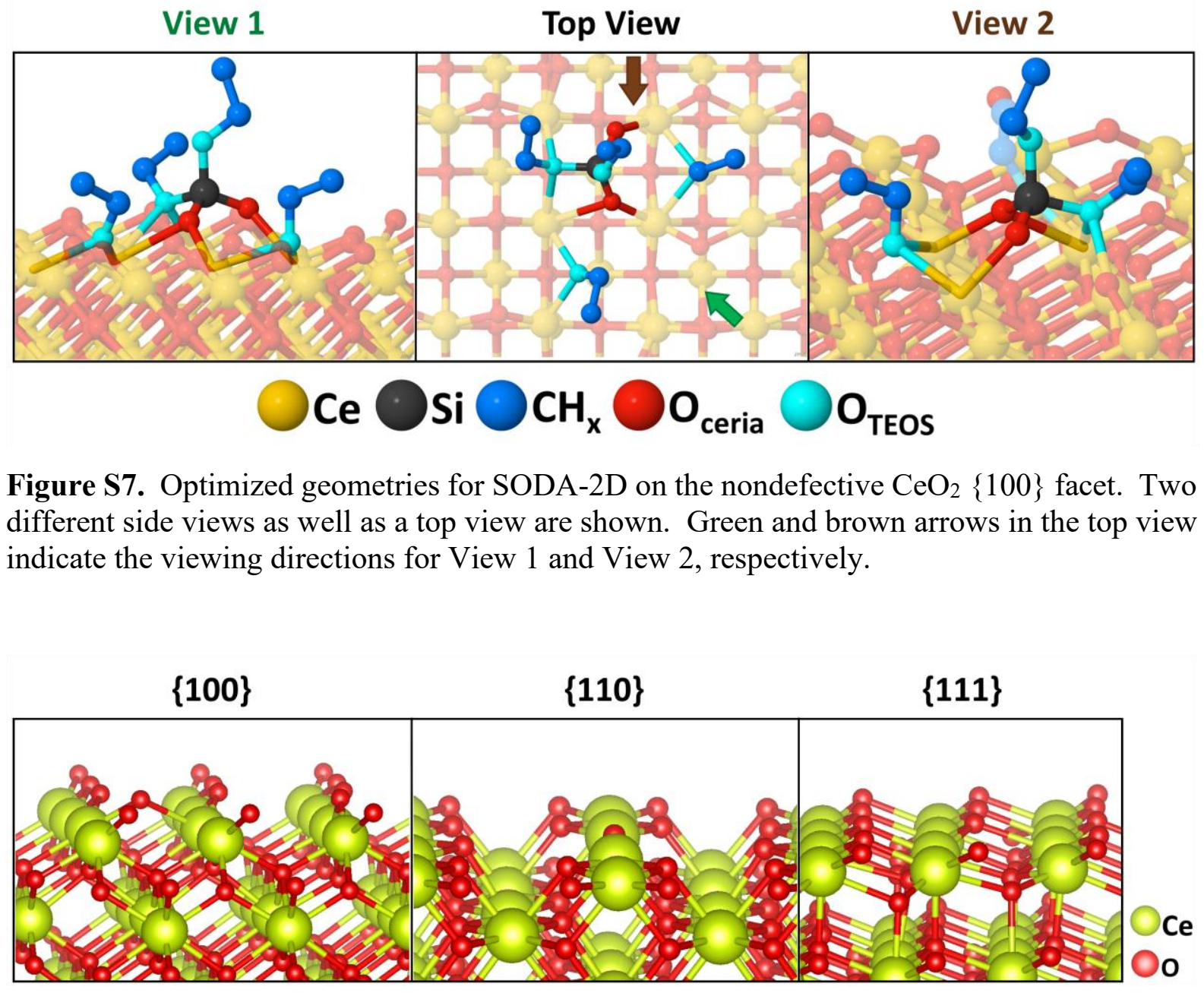

Figure S8. Optimized geometries for the defective $\mathrm{CeO}_{2}$ facets.

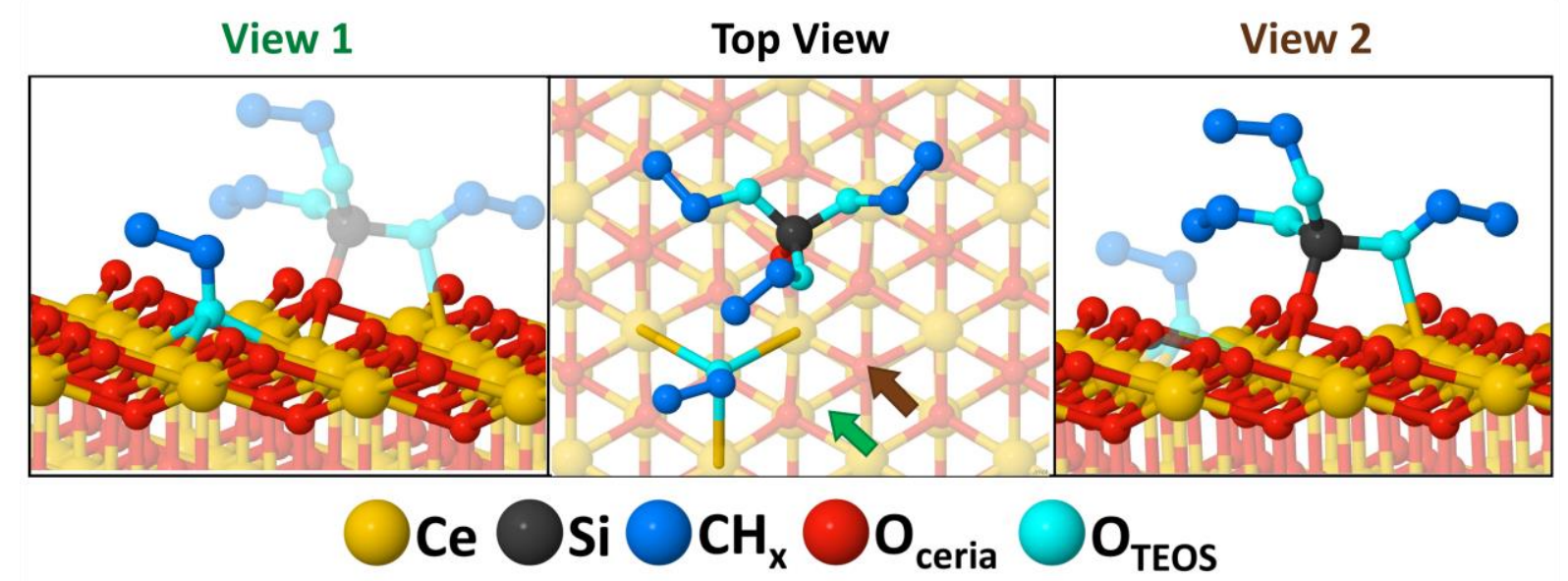

Figure S9. Optimized geometries for SODA on the defective $\mathrm{CeO}_{2}\{111\}$ facet. Two different side views as well as a top view are shown. Green and brown arrows in the top view indicate the viewing directions for View 1 and View 2, respectively. 


\section{REFERENCES}

(1) Artini, C.; Pani, M.; Carnasciali, M. M.; Buscaglia, M. T.; Plaisier, J. R.; Costa, G. A. Structural Features of Sm- and Gd-Doped Ceria Studied by Synchrotron X-Ray Diffraction and $\mu$-Raman Spectroscopy. Inorg. Chem. 2015, 54, 4126-4137.

(2) Mohanty, B. C.; Lee, J. W.; Yeon, D.-H.; Jo, Y.-H.; Kim, J. H.; Cho, Y. S. Dopant Induced Variations in Microstructure and Optical Properties of $\mathrm{CeO}_{2}$ Nanoparticles. Mater. Res. Bull. 2011, 46, 875-883.

(3) Boonstra, L.; Mijlhoff, F.; Renes, G.; Spelbos, A.; Hargittai, I. The Molecular Structure of Tetramethoxysilane in the Gas Phase, an Electron Diffraction Study. J. Mol. Struct. 1975, 28, 129-135.

(4) Skorodumova, N.; Baudin, M.; Hermansson, K. Surface Properties of $\mathrm{CeO}_{2}$ from First Principles. Phys. Rev. B 2004, 69, 075401.

(5) Nolan, M.; Grigoleit, S.; Sayle, D. C.; Parker, S. C.; Watson, G. W. Density Functional Theory Studies of the Structure and Electronic Structure of Pure and Defective Low Index Surfaces of Ceria. Surf. Sci. 2005, 576, 217-229.

(6) Désaunay, T.; Ringuedé, A.; Cassir, M.; Labat, F.; Adamo, C. Modeling Basic Components of Solid Oxide Fuel Cells Using Density Functional Theory: Bulk and Surface Properties of $\mathrm{CeO}_{2}$. Surf. Sci. 2012, 606, 305-311.

(7) Nolan, M. Enhanced Oxygen Vacancy Formation in Ceria (111) and (110) Surfaces Doped with Divalent Cations. J. Mater. Chem. 2011, 21, 9160-9168.

(8) Liu, Z.; Li, X.; Mayyas, M.; Koshy, P.; Hart, J. N.; Sorrell, C. C. Growth Mechanism of Ceria Nanorods by Precipitation at Room Temperature and Morphology-Dependent Photocatalytic Performance. CrystEngComm 2017, 19, 4766-4776.

(9) Gennard, S.; Cora, F.; Catlow, C. R. A. Comparison of the Bulk and Surface Properties of Ceria and Zirconia by $a b$ initio Investigations. J. Phys. Chem. B 1999, 103, 10158-10170. 